\title{
KEEFEKTIFAN PERANGKAT PEMBELAJARAN INVESTIGATION BASED MULTI REPRESENTATION UNTUK MENINGKATKAN KETERAMPILAN PEMECAHAN MASALAH
}

\author{
Kurnia Retno Safitri ${ }^{1 *}$, Budi Jatmiko ${ }^{2}$, Elok Sudibyo ${ }^{3}$ \\ Pascasarjana Universitas Negeri Surabaya ${ }^{1,2,3}$ \\ *Coressponding Author: Kurniars1396@gmail.com
}

DOI: $10.24929 /$ lensa.v10i1.94

\begin{abstract}
ABSTRAK
Tujuan penelitian ini adalah untuk menganalisis keefektifan perangkat pembelajaran model Investigation Based Multi Representation (IBMR) yang telah dikembangkan dan melalui tahap validasi untuk membantu meningkatkan keterampilan pemecahan masalah siswa. Desain yang digunakan adalah one group pre-test post-test, yang diterapkan pada materi Hukum Newton kelas X MIA di SMA Negeri 18 Surabaya. Data penelitian dikumpulkan dari nilai pre-test dan post-test siswa dan hasil pengamatan keterlaksanaan pembelajaran dan aktivitas siswa. Hasil tes keterampilan pemecahan masalah dianalisis menggunakan uji-t berpasangan dan $n$-gain. Hasil penelitian menunjukkan bahwa pembelajaran menggunakan model IBMR adalah efektif untuk meningkatkan keterampilan pemecahan masalah siswa dengan kategori sedang. Peningkatan keterampilan pemecahan masalah siswa menggunakan model IBMR didukung berdasarkan keterlaksanaan pembelajaran dan aktivitas siswa dengan kategori baik.
\end{abstract}

Kata kunci: Hukum Newton, multi representasi, pemecahan masalah

\begin{abstract}
The purpose of this study is to analyze the effectiveness of learning model Investigation-Based Multi Representation Learning (IBMR) which has been developed and through validation to help improve student's problem solving skills. The design used was a group pre-test post-test, which was applied to Newton's Law material at class $X$ MIA SMA Negeri 18 Surabaya. Research data were collected from student's pre-test and post-test scores and observations of the implementation of learning and student activities. The results of problem solving skills tests were performed using paired t-test and $n$-gain. The results showed that learning using the IBMR model was effective for improving student's problem solving learning in the medium category. Improving student's problem solving skills using the IBMR model is supported based on the implementation of learning and student activities in either category.
\end{abstract}

Keyword: Newton's Law, multi representation, problem solving

\section{Pendahuluan}

Pendidikan merupakan bagian yang sangat penting dalam kehidupan bermasyarakat, sehingga pendidikan harusnya dikelola dengan baik untuk mewujudkan sumber daya manusia yang lebih unggul. Dengan demikian kegiatan yang berhubungan dengan pendidikan sebaiknya diorganisasikan dengan baik [1]. Apabila dikaitkan dengan pembelajaran yang ada di Indonesia, saat ini Indonesia telah menerapkan kurikulum 2013 sebagai dasar pembelajaran. Kurikulum 2013 mengimplementasikanpembelajaran yang berpusat kepada siswa (student centered) dan guru menekankan siswa untuk lebih aktif pada proses penggalian, penemuan, dan 
menciptakan pembelajaran secara kontekstual [9]. Sehingga dapat dikatakan bahwa perubahan pada kurikulum 2013 jelas dapat menjadi salah satu bagian penting dalam menjalani pembelajaran yang sesuai dengan abad 21 .

Terdapat beberapa tuntutan keterampilan pada pembelajaran abad 21 , yaitu critical thinking and problem solving, communication, collaboration, dan creativity and innovation. Keterampilan tersebut diharapkan dapat menghasilkan sumber daya manusia yang dapat menguasai berbagai bentuk keterampilan abad ke-21 [7]. Sebagian besar peneliti mendefinisikan keterampilan abad 21 adalah sebagai ways of thinking, ways of working, tools for working, and living in the world [2]. Diantara keterampilan abad 21 yang telah disebutkan ada beberapa keterampilan yang masih sangat rendah dimiliki oleh siswa di Indonesia, salah satunya adalah keterampilan dalam memecahkan masalah (problem solving). Rendahnya keterampilan pemecahan masalah tersebut dapat dilihat dari pencapaian nilai Programme for International Student Assessment (PISA). Berdasarkan data pada OECD, Indonesia berpatisipasi di PISA sejak tahun 2000 dengan skor rata-rata yang masih jauh dengan skor rata-rata Internasional. Hal tersebut juga terjadi pada tahun berikutnya sampai yang terbaru adalah hasil PISA di tahun 2018 yang menunjukkan bahwa Indonesia mendapatkan skor 396 yang terbilang masih jauh dengan rata-rata Internasional [17][18]. Tidak hanya dalam soal PISA, ternyata kesulitan dalam menyelesaikan soal-soal juga telah ditemukan di sebagaian besar siswa di sekolah, salah satunya pada mata pelajaran fisika.

Siswa sering mengalami kesulitan dalam memahami hubungan antara masalah dan konsep yang terlibat dalam permasalahan fisika [10][22]. Siswanto, Susantini, \& Jatmiko dalam penelitiannya menyebutkan bahwa kesulitan dalam menyelesaikan soalsoal fisika disebabkan karena rendahnya kemampuan siswa dalam merepresentasikan konsep fisika [26]. Nguyen et.al dalam penelitiannya menyebutkan bahwa siswa sering mengalami kesulitan dalam menyelesaikan permasalahan fisika terutama dalam representasi numerik, grafis, dan persamaan [15]. Oleh karena itu, diperlukan model pembelajaran yang dapat digunakan untuk membantu meningkatkan keterampilan pemecahan masalah siswa pada fisika salah satunya dalam bentuk multi representasi. Ainsworth dalam Haratua dan Sirait [8] menyebutkan bahwa fungsi dari multi representasi yaitu, untuk melengkapi representasi lain, untuk membatasi interpretasi, dan untuk membangun pemahaman yang lebih dalam. Siswa yang memiliki kategori terampil dalam pemecahan masalah maka akan terbiasa menggunakan representasi matematika seperti grafik dan diagram, sedangkan siswa yang kurang terampil dalam pemecahan masalah maka dapat menggunakan representasi berupa gambar [25]. Penggunaan representasi yang lebih dari satu dapat menekankan aspek konseptual pada siswa [21]. Sehingga dibutuhkan suatu model pembelajaran yang dapat membantu siswa memecahkan masalah fisika dalam bentuk multi representasi. Model pembelajaran berbentuk multi representasi yang dapat digunakan yaitu model Investigation Based Multiple Representation (IBMR). IBMR memiliki lima sintaks, yaitu orientasi, investigasi, multi representasi, aplikasi, dan evaluasi [24].

Indikator pemecahan masalah yang digunakan diadaptasi berdasarkan pemecahan masalah Polya [5] yaitu memahami masalah, membuat rencana penyelesaian, melaksanakan rencana, mengecek dan mengevaluasi. Gopinath \& Lertlit menyebutkan langkah-langkah pemecahan masalah Polya lebih efisien [4]. Proses penyelesaian masalah dilakukan menggunakan keterampilan proses sains yaitu merumuskan masalah, merumuskan hipotesis, merencanakan percobaan, melakukan percobaan, menganalisis data, dan menyimpulkan [16].

Dalam penelitian ini, perangkat pembelajaran model IBMR diimplementasikan dengan pendekatan kontekstual, dimana guru membawa dunia nyata ke dalam kelas dan mendorong siswa untuk menghubungkan antara pengetahuan yang dimilikinya dengan kehidupan sehari-hari [13]. Pendekatan kontekstual melibatkan siswa secara aktif melakukan diskusi kelompok belajar berdasarkan masalah nyata, dan juga pemecahan masalah [11]. Materi yang dipilih adalah Hukum Newton karena konsep di dalamnya dapat disajikan secara multi representasi sehingga dapat digunakan untuk membantu meningkatkan keterampilan pemecahan masalah siswa. 


\section{Metode}

Perangkat pembelajaran dikembangkan menggunakan rancangan 4-D yang terdiri dari tahap define, design, develop, dan disseminate. Kemudian penelitian ini menggunakan desain one group pre-test post-test, yaitu U1>L>U2 [19]. Sebelum pembelajaran dimulai maka siswa diberikan pre-test tentang keterampilan pemecahan masalah (U1), selanjutnya diberikan pembelajaran IBMR (L), kemudian diberikan post-test (U2). Penelitian ini dilakukan pada semester Genap tahun ajaran 2019/2020 pada siswa kelas X-MIA 1 dan X MIA-3 di SMA Negeri 18 Surabaya dengan materi yang dipilih Hukum Newton. Metode pengumpulan data yang digunakan berupa observasi dan pemberian tes. Pengumpulan data berupa observasi dilakukan untuk mendapatkan data keterlaksanaan pembelajaran dan aktivitas siswa, kemudian pemberian tes dilakukan untuk mendapatkan data hasil keterampilan pemecahan masalah siswa. Kemudian data yang didapatkan dianalisis menggunakan uji-t berpasangan dan $\mathrm{n}$-gain. $\mathrm{N}$-gain dilakukan untuk menganalisis apakah ada peningkatan nilai siswa antara pre-test dan post-test. Kemudian dilakukan uji-t berpasangan pada nilai n-gain. Kategori keterlaksanaan pembelajaran dan aktivitas siswa dikatakan tidak terlaksana jika interval skor 0\%-24\%, terlaksana kurang baik jika interval skor $25 \%-49 \%$, terlaksana baik jika interval skor 50\%-74\%, terlaksana sangat baik jika interval skor 75\%-100\%. Kategori $\mathrm{N}$-gain dikatakan rendah jika skor $0.70 \leq \mathrm{n}$-gain, sedang jika skor $0.30 \leq \mathrm{n}$-gain < 0.70 , tinggi jika skor $0.70 \leq \mathrm{n}$-gain [6].

\section{Hasil dan diskusi}

Setelah didapatkan hasil pre-test dan post-test dari keterampilan pemecahan masalah menggunakan pembelajaran IBMR. Hasil analisis pre-test dan post-test telah disajikan pada Tabel 1.

Tabel 1. Hasil uji normalitas dan uji homogenitas $(\alpha=0.05)$

\begin{tabular}{|c|c|c|c|c|c|c|c|c|c|}
\hline \multirow[b]{2}{*}{ Kelas } & \multirow[b]{2}{*}{ Nilai } & \multirow[b]{2}{*}{$\begin{array}{c}\text { Rerat } \\
\text { a }\end{array}$} & \multicolumn{2}{|c|}{$\mathrm{N}$-gain } & \multicolumn{2}{|c|}{ Normalitas } & \multicolumn{3}{|c|}{ Homogenitas } \\
\hline & & & Skor & Kriteria & $\begin{array}{l}\text { Sig. (2- } \\
\text { tailed) }\end{array}$ & Normal & $\mathrm{F}$ & Sig. & Homogen \\
\hline \multirow{2}{*}{ X MIA 1} & Pre-test & 41.25 & 0.48 & Sedang & 0903 & $\mathrm{~V}=$ & \multirow{4}{*}{0.439} & \multirow{4}{*}{0.920} & \multirow{4}{*}{ Ya } \\
\hline & Post-test & 69.21 & 0.48 & sedang & 0.903 & Ya & & & \\
\hline \multirow{2}{*}{ X MIA 3} & Pre-test & $\begin{array}{l}45.88 \\
6881\end{array}$ & \multirow[t]{2}{*}{0.42} & \multirow[t]{2}{*}{ Sedang } & \multirow{2}{*}{0.373} & \multirow{2}{*}{ Ya } & & & \\
\hline & Post-test & 68.81 & & & & & & & \\
\hline
\end{tabular}

Tabel 2. Hasil uji-t berpasangan $(\alpha=0.05)$

\begin{tabular}{|c|c|c|}
\hline \multirow{2}{*}{ Kelas } & \multicolumn{2}{|c|}{ Uji-t berpasangan } \\
\cline { 2 - 2 } & Sig. (2-tailed) & Keputusan \\
\hline X MIA 1 & 0.000 & \multirow{2}{*}{ H0 ditolak } \\
\hline X MIA 3 & 0.000 & \\
\hline
\end{tabular}

Berdasarkan hasil analisis data yang telah disajikan pada Tabel 1 diketahui dari nilai $\mathrm{n}$ gain menunjukkan peningkatan antara nilai pre-test dan post-test pada kelas X MIA 1 sebesar 0.48 dengan kategori sedang dan pada kelas X MIA 3 sebesar 0.42 dengan kategori sedang. Pada Tabel 2 Hasil uji-t berpasangan juga menunjukkan bahwa nilai sig. (2-tailed) $<0.05$, maka $\mathrm{H}_{0}$ ditolak. Keefektifan perangkat pembelajaran dinilai dari beberapa indikator salah satunya apabila rata-rata keefektifan dari n-gain berkategori minimal sedang.

Berdasarkan hasil penelitian yang telah dilakukan didapatkan bahwa perangkat pembelajaran menggunakan model IBMR yang diterapkan efektif untuk meningkatkan keterampilan pemecahan masalah. Hasil ini mendukung penelitian sebelumnya yang menyebutkan bahwa multi representasi efektif digunakan dalam memahami konsep dan 
pemecahan masalah [13][12][23]. Peningkatan hasil keterampilan pemecahan masalah siswa juga didukung oleh beberapa faktor diantaranya keterlaksanaan pembelajaran oleh guru di kelas dan aktivitas siswa selama proses pembelajaran. Hasil keterlaksanaan pembelajaran dan aktivitas siswa disajikan pada Tabel 3.

Tabel 3. Hasil keterlaksanaan pembelajaran dan aktivitas siswa

\begin{tabular}{|c|c|c|c|c|c|c|c|c|}
\hline \multirow{3}{*}{$\begin{array}{c}\text { Aspek yang } \\
\text { dinilai }\end{array}$} & \multicolumn{4}{|c|}{ Keterlaksanaan pembelajaran } & \multicolumn{4}{|c|}{ Aktivitas siswa } \\
\hline & \multicolumn{2}{|c|}{ X MIA 1} & \multicolumn{2}{|c|}{ X MIA 3} & \multicolumn{2}{|c|}{ X MIA 1} & \multicolumn{2}{|c|}{ X MIA 3} \\
\hline & Skor & $\mathrm{R}(\%)$ & Skor & $\begin{array}{c}\mathrm{R} \\
(\%)\end{array}$ & Skor & $\begin{array}{c}\mathrm{R} \\
(\%)\end{array}$ & Skor & $\begin{array}{l}\mathrm{R} \\
(\%)\end{array}$ \\
\hline Orientasi & 3.80 & \multirow{7}{*}{98.57} & 4.00 & \multirow{7}{*}{97.20} & 3.46 & \multirow{7}{*}{97.40} & 3.84 & \multirow{7}{*}{96.54} \\
\hline Investigasi & 4.00 & & 3.56 & & 4.00 & & 3.72 & \\
\hline $\begin{array}{c}\text { Multi } \\
\text { representasi }\end{array}$ & 3.83 & & 3.67 & & 3.50 & & 3.50 & \\
\hline Aplikasi & 4.00 & & 4.00 & & 3.33 & & 4.00 & \\
\hline Evaluasi & 4.00 & & 4.00 & & 4.00 & & 4.00 & \\
\hline Penutup & 3.67 & & 4.00 & & 4.00 & & 4.00 & \\
\hline Rata-rata & 3.88 & & 3.87 & & 3.72 & & 3.84 & \\
\hline
\end{tabular}

Keterangan: $\mathrm{R}=$ Reliabilitas

Tabel 3 menyajikan data hasil keterlaksanaan pembelajaran dan aktivitas siswa selama berlangsungnya pembelajaran menggunakan model IBMR. Keterlaksanaan pembelajaran pada kelas X MIA 1 dan X MIA 3 mendapatkan skor rata-rata masingmasing 3.88 dan 3.87. Sedangkan aktivitas siswa pada kelas X MIA 1 dan X MIA 3 mendapatkan skor rata-rata masing-masing 3.72 dan 3.84. Skor pada keterlaksanaan pembelajaran dan aktivitas siswa menunjukkan interval $3.25<$ skor $\leq 4.00$ dengan kriteria sangat baik [20]. Berdasarkan hasil tersebut dapat dikatakan bahwa keterlaksanaan pembelajaran dan aktivitas siswa merupakan faktor pendukung peningkatan hasil belajar siswa [24].

\section{Simpulan}

Berdasarkan hasil penelitian dan hasil diskusi dapat disimpulkan bahwa pembelajaran fisika pada materi Hukum Newton menggunakan model Investigation Based Multiple Representation (IBMR) dapat meningkatkan keterampilan pemecahan masalah siswa dengan kategori sedang. Peningkatan keterampilan pemecahan masalah di dukung dengan keterlaksanaan pembelajaran dan aktivitas siswa yang sangat baik.

\section{Sugesti}

Untuk meningkatkan keterampilan pemecahan masalah sebaiknya perlu dilatihkan kebiasaan literasi, karena kemampuan literasi yang baik akan membantu mempermudah siswa dalam menyelesaikan masalah. Guru disarankan untuk merancang kegiatan pembelajaran dengan memaksimalkan penggunaan multi representasu tidak hanya verbal ataupun matematis tetapi juga representasi grafik dan gambar untuk melatihkan kemampuan representasi siswa. Kemudian harus dilakukan manajemen waktu dengan baik sehingga pembelajaran dengan multi representasi dapat diterapkan semaksimal mungkin. 


\section{Daftar Pustaka}

Arifin, A. H. The Implementation Of Multicultural Education In The Educational Practices In Indonesia. Jurnal Pembangunan Pendidikan: Fondasi Dan Aplikasi, 1(1), 7282.2012

Binkley et.al. Defining Twenty-First Century Skills, Assessment and Teaching of 21st Century Skills, pp, 17-64.2012

Cock, M. De. Representation use and strategy choice in physics problem solving. Physical Review Special Topics - Physics Education Research, 20117(July), 115.2012

Gopinath, S., \& Lertlit, S. The Implementation of Polya' s Model in Solving ProblemQuestions in Mathematics by Grade 7 Students. Suranaree J. Soc. Sci., 11(1), 4760.2017

Gray, C. A. The Impact of Applying the First Two Steps of Polya ' s Four Problem Solving Steps in an Advanced Mathematics Classroom. 2018

Hake, R. R. Interactive engagement v.s traditional methods: six- thousand student survey of mechanics test data for introductory physics courses. American Journal of Physics.1999

Handajani, S., Pratiwi, H., \& Mardiyana. The 21 st century skills with model eliciting activities on linear program. Journal of Physics.2018

Haratua, T., \& Sirait, J. Representations Based Physics Instruction to Enhance Students ' Problem Solving. American Journal of Educational Research, 4(1), 1-4.2016

Hosnan. Pendekatan Saintifik dan Kontekstual dalam Pembelajaran Abad 21. Bogor : Ghalia Indonesia.2014

Ince, E. An Overview of Problem Solving Studies in Physics Education. Journal of Education and Learning, 7(4), 191-200.2018

Kartikaningtyas, V., Kusmayadi, T., \& Riyadi. Contextual Approach with Guided Discovery Learning and Brain Based Learning in Geometry Learning. International Conference on Mathematics and Science Education, Series: Journal of Physics.2017

Kurnaz, M. A., \& Arslan, A. S. Effectiveness of Multiple Representations for Learning Energy Concepts: Case of Turkey. Procedia - Social and Behavioral Sciences, 116, 627-632.2014

Kurnianingsih, C., \& Susilaningsih, E. Analysis of Science Process Skills of Students through Contextual Approach on Science-Chemistry Learning in Taiwan, 190196.2017

Mendikbud RI. Peraturan Menteri Pendidikan dan Kebudayaan Republik Indonesia Nomor 65 Tahun 2013 tentang Standar Proses Pendidikan Dasar dan Menengah.2013

Nguyen, D. H., \& Rebello, N. S. Students' Difficulties With Multiple Representations in Introductory Mechanics (US-China Education Review), vol 8 no 5 pp 559-569.2010

Nur, M. Modul Keterapilan-keterampilan Proses Sains. Surabaya: Pusat Sains dan Matematika Sekolah Unesa.2011 
OECD. PISA 2015 Assessment and Analyti- cal Framework: Science, Reading, Mathematic and Financial Literacy, PISA, OECD Publish-ing, Paris.2016

OECD. PISA 2018 Results Combined Evecutive Summaries.2019

Prabowo. Metodologi Penelitian (sains dan pendidikan sains). Surabaya: Unesa University Press.2011

Ratumanan, T. G. \& Laurens T. Penilaian Hasil Belajar pada Tingkat Satuan Pendidikan. Surabaya: Unesa University Press.2011

Rau, M.A. \& Matthews, P.G.,. How to make " more " better? Principles for effective use of multiple representations to enhance students ' learning about fractions. ZDM Mathematics Education.2017

Reddy, M. V. B., \& Panacharoensawad, B. Students Problem-Solving Difficulties and Implications in Physics: An Empirical Study on Influencing Factors. Journal of Education and Practice, 8(14), 59-62.2017

Siswanto, J., Susantini, E., \& Jatmiko, B. Kepraktisan Model Pembelajaran Investigation Based Multiple Representation ( IBMR ) dalam Pembelajaran Fisika. Jurnal Penelitian Pembelajaran Fisika, 7(September), 127-131.2016

Siswanto, J., Susantini, E., \& Jatmiko, B. Multi-representation based on scientific investigation for enhancing students ' representation skills. Journal of Physics.2018

Theasy, Y., Wiyanto, \& Sujarwata. Multi-representation ability of students on the problem solving physics. Journal of Physics.2018 